\title{
Study of Diagnostic Role of Urine Malaria Test in Patients with Falciparum Malaria Admitted in Abbassia Fever Hospital
}

\author{
Hossam Ibrahim Mohamed ${ }^{1}$, Ismael Mahmoud Ali Moharam², \\ Ahmed Ragab El-Gazzarah ${ }^{1}$, Hesham El-Saeed Mohamed Sallam ${ }^{3}$ \\ ${ }^{1}$ Tropical Medicine Department, Faculty of Medicine, Menoufia University, Menoufia, Egypt \\ ${ }_{2}^{2}$ Parasitology Department, Faculty of Medicine, Menoufia University, Menoufia, Egypt \\ ${ }^{3}$ Abbasia Fever Hospital, Ministry of Health, Cairo, Egypt
}

Corresponding Author

Hesham El Saeed

Mohamed Sallam

Mobile:

$+201000562296$

E mail: drsokawy@gmail.com

Key words: Falciparum malaria, $U M T$
Background and study aim: Malaria morbidity and mortality can be prevented or minimized by rapid diagnosis and treatment. Blood based rapid diagnostic tests (bRDT) for malaria are currently in use but other body fluids specific diagnostic test kits are being developed. One of these tests is Urine Malaria Test (UMT) dipstick, it is a one-step test used to detect Histidine Rich Protein 2 (HRP2), a polyhistidine antigen of plasmodium falciparum (Pf) in urine of affected patients. The aim of the present study was to evaluate the role of UMT in diagnosis of Pf malaria and its ability to detect the limits of Pf parasitemia in febrile patients admitted to Abbasia Fever Hospital, Egypt.

Patients and Methods: This study was conducted on 52 Pf malarial patients who were admitted to Abbassia Fever Hospital. Patients were subjected to meticulous history taking, clinical examination, routine laboratory investigations, abdominal ultrasound, blood film microscopy for malaria, rapid blood test (RBT) and UMT. Confirmed Pf malaria

\section{INTRODUCTION}

Malaria is a serious, infectious, preventable and curable mosquito born protozoal disease with significant world-wide morbidity and mortality [1]. Parasite-based diagnostic tools [blood film microscopy which detect the parasite in blood film and Rapid diagnostic tests (RDTs) which detect malarial antigen and/or antibody] as well as molecular techniques for detection of genetic material as PCR (limited to research settings) are essential to confirm the diagnosis [2].

Blood film microscopy is sensitive, accurate and inexpensive gold standard method in diagnosis of malaria, however in the studied patients was based on the presence of positive parasite-based tests (+ve blood film microscopy with/without RBT for Pf malaria).

Results: The UMT was positive in 50\% of cases with $50 \%$ false negative results in parasitologically confirmed Pf malarial patients. Sixteen patients presented with parasitemia $\leq 0.5 \%$ (ranged between $0.1 \%$ to $\leq 0.5 \%$ ) in thick blood film and there was non-significant difference between positive and negative UMT in these patients $[43.75 \%$ of cases were +ve versus $56.25 \%$-ve test $(\mathrm{p}=0.280) \quad$ with sensitivity $(55.56 \%)$, specificity $(71.43 \%)$ and accuracy $(62.5 \%)]$. The +ve UMT results were significantly related to higher parasitemia, lower Glasgow coma scale, lower platelet count and severe disease.

Conclusion: The UMT is simple, easy, self-performed and promising test in diagnosis of Pf malaria, however the sensitivity and specificity were apparently low.

it relies mainly on the experience of the microscopist, quality of the slides, stain, microscope, time spent in examination of the slides and it is not available in areas with low resources. RDT can help in diagnosis of malaria in resource limited areas [1].

Correct diagnosis in malaria-endemic areas is particularly important for the most vulnerable population groups, such as young children and non-immune populations, in whom falciparum malaria can be rapidly fatal. High specificity will improve the diagnosis, reduce the unnecessary antimalarial treatment and reduce rate of resistance [1]. 
Experts convened at the inaugural meeting of the Malaria Policy Advisory Committee, held in Geneva in early 2012, updated the WHO recommendations for procurement of RDTs. Products should be selected according to the following criteria (for the detection of $\mathrm{P}$. falciparum $(\mathrm{Pf})$ or $\mathrm{P}$. vivax $(\mathrm{Pv})$ in all transmission settings, the panel detection score against $\mathrm{Pf}$ or $\mathrm{Pv}$ samples should be at least $75 \%$ at 200 parasites $/ \mu \mathrm{L}$ with $<10 \%$ false +ve results and $<5 \%$ invalid rate) [3].

The performance of rapid malaria blood test for diagnosis of malaria in urine and blood samples in comparison with microscopy showed much lower sensitivity and specificity of the test in urine samples when compared with the results of the test in blood samples [4].

UMT dipstick has been developed in the last few years. The test is a one-step test that detects HRP2 (a poly histidine antigen of Pf) in urine of affected patients [5]. People can test themselves for the presence of malaria at home without the need for health facility nor personnel to carry out the test [6].

\section{Aim of the study}

The aim of the present study was to evaluate the role of UMT in diagnosis of Pf malaria and its ability to detect the limits of Pf parasitemia in febrile patients admitted to Abbasia Fever Hospital, Egypt.

\section{PATIENTS AND METHODS}

This study was conducted on 52 Pf malarial patients selected from 120 febrile patients and who were admitted to Abbasia Fever Hospital during the period from November 2016 to October 2017; they were 41 males $(79 \%) \& 11$ females $(21 \%)$; Their ages ranged between 5 years to 62 years with median age value 30.5 years.

\section{Patients inclusion criteria:}

- Patients presented to Abbassia Fever Hospital with fever $\geq 37.5^{\circ} \mathrm{C}$ as first presentation with history of arrival from endemic malarious area for up to one month.

- Positive blood film microscopy (thick and thin film) with or without positive RBT for Pf malaria.

\section{The following patients were excluded:}

- History of Pf malaria and used antimalarial drugs (prophylactic and/or therapeutic) during the last two months.
- Species of malaria other than Pf malaria.

- Renal diseases presented with proteinuria as it could affect the results of UMT.

- Non-malarial patients.

- Non-febrile patients.

The study was conducted in accordance with the Declaration of Helsinki. All participants provided written informed consent, and the Ethics Committee of Faculty of Medicine, Menoufia University approved the study protocol.

\section{All Patients were subjected to the following:}

Written consent prior to study enrollment.

Full detailed history taking with stress on past history of travelling to a malaria endemic area within the last month and complete meticulous clinical examination to assess the clinical suspicion of malaria and to assess the severity of the disease and the presence of complications.

Imaging study : abdominal ultrasonography was done once at admission to assess size \& consistency of liver \& spleen to all patients and done daily to see viability of the fetus to one pregnant female. Chest $\mathrm{x}$-ray was done for routine cardiopulmonary assessment except for one pregnant female.

\section{Laboratory investigations:}

Blood sampling: Venous blood withdrawn to make parasitological diagnosis [drops of blood taken to make blood film (thin and thick) [7] and RBT [8]), also for CBC, liver profile (AST, ALT, serum albumin \& bilirubin), coagulation profile (prothrombin time \& INR), kidney function tests (blood urea \& serum creatinine) and random blood sugar level. Arterial blood samples were obtained from radial artery for arterial blood gases (ABG) in twenty-two patients with acidotic breathing.

Parasitological diagnosis: Malaria parasites were best seen under 1000x magnification using the oil immersion objective lens; smear evaluation included examination of at least 200 to 500 fields or examination for 20 to 30 minutes. Thin and thick blood films were done to all cases. The thin film confirmed the presence of Pf in all studied cases (the presence of ring forms of trophozoites, banana shaped gametocytes and rarely schizonts of Pf) and was used for counting parasitemia $(>0.5 \%)$ in relation to RBCs (the count was confirmed by thick film). Moreover, parasite counting in relation to WBCs using thick film 
was done for 16 patients with parasitemia $(\leq 0.5 \%)$ in thin blood film.

Urine Malaria Test ${ }^{\text {TM }}$ (UMT): Urine sampling were collected in sterile cups from all cases included in the study to perform UMT (Fyodor Urine malaria test made in USA By Fyodor Biotechnologies, Inc - Lot 7014978) which is an in vitro immunochromatographic monoclonal antibody test for the qualitative detection of specific Pf protein fragments shed in the urine of febrile malaria patients. The test strip consists of gold-conjugated capture antibody, as well as proprietary test and control line antibodies that are immobilized at specific individual sites on the nitrocellulose strip. The antibody reagents interact with the corresponding malaria parasite proteins or protein fragments therefrom [6].

Procedure: The end of the test strip was dipped in the freshly collected urine sample in clean and dry cup provided in the kit with arrows pointing down and was remained standing in the sample for 25 minutes before reading the results.

Interpretation of Results: Test results are interpreted by the presence or absence of visually detectable pink to purple lines. A positive test result (the test line and control line were colored), negative test results (colored control line \& uncolored test line) while invalid test result (uncolored test line and control line) Figure (1).

\section{Statistical Analysis}

All data were collected, tabulated and statistically analyzed using SPSS 19.0 for windows (SPSS Inc., Chicago, IL, USA) \& MedCalc 13 for windows (MedCalc Software bvba, Ostend, Belgium). and for all the analysis a $\mathrm{p}$ value $<0.05$ was considered statistically significant.

\section{RESULTS}

About $90 \%$ of studied malarial patients aged $>17$ years. Male (78.85\%): Female $(21.15 \%)$ ratio in studied malarial patients was 3.73: 1 . In order of frequency, the source of malaria infection in studied patients were North and South Sudan (50\% of cases), Nigeria (25\% of cases), Chad (7.69\% of cases) and Genia (5.77\% of cases). The studied malarial patients were 37 non-Egyptian visitors $(71.15 \%)$ and 15 Egyptian travelers (28.85\%) (Table 1). Regarding occupation, about half of cases were non-worker $(53.85 \%)$ and about one fourth (26.92\%) were students (Figure 2).
Fever was a constant finding in all cases followed by vomiting $(50 \%)$, abdominal pain $(46.15 \%)$, acidotic like breathing (42.24\%), pallor (25\%) and various degrees of disturbed conscious level $(21.15 \%)$. Other apparent less frequent features were hepatomegaly with or without splenomegaly $(17.3 \%)$, jaundice $(11.54 \%)$, prostration and significant oliguria (5.77\% for each) and pulmonary edema, convulsions and cyanosis $(3.84 \%$ for each) (Table 2).

ABG done to 22 patients with acidotic like breathing proved the presence of definite metabolic acidosis (bicarb $<15 \mathrm{mEq} / \mathrm{l}$ ) in 3 patients $(5.76 \%$ ). The mean $\mathrm{Hb}$ concentration was $10.81 \pm 2.65$ $\mathrm{gm} / \mathrm{dl}$ with severe anemia $(\mathrm{Hb}<7 \mathrm{gm})$ in $21.15 \%$ of cases, mean platelet count was $74.88 \pm 38.72$ $\times 10^{3} / \mu 1$ with thrombocytopenia (platelet $<90 \times$ $10^{3} / \mu \mathrm{l}$ ) in $73.07 \%$ of cases, mean serum bilirubin was $2.36 \pm 5.18 \mathrm{mg} \%$ with values more than 3 $\mathrm{mg} \%$ in $7.69 \%$. Mean serum creatinine level was $1.62 \pm 1.20 \mathrm{mg} \%$ with values $>3 \mathrm{mg} \%$ in $5.76 \%$. None of the studied malarial patients presented with hypoglycemia on admission or developed hypoglycemia during follow up (TABLE 3).

RBT and blood film for Pf malaria were +ve in all studied patients (100\%), while UMT was +ve in half of studied cases (50\%). Parasitological malarial index revealed the presence of high parasitemia (index $>4$ ) in 3 patients (Table 4).

The present study revealed that 36 out of 52 patients $(69.12 \%)$ had uncomplicated and 10 out of 52 patients $(19.23 \%)$ had severe malaria [GCS $<11(11.52 \%)$ (2 of them had cerebral malaria), S. bilirubin $>3 \mathrm{gm}(11.52 \%)$, prostration $(5.76 \%)$, metabolic acidosis with HCO3- <15 (5.76\%), renal failure $(5.76 \%)$, pulmonary edema $(3.84 \%)$, multiple convulsions (3.84\%)], in addition one pregnant female and 5 children aged $\leq 17$ years managed as severe malaria according WHO definition of severe Pf malaria (Table 5).

The UMT was positive in $50 \%$ of cases with $50 \%$ false negative results in parasitologically confirmed Pf malarial patients. Sixteen patients presented with parasitemia $\leq 0.5 \%$ (ranged between $0.1 \%$ to $\leq 0.5 \%$ ) in thick blood film and there was non-significant difference between positive and negative UMT in these cases (43.75\% of cases were +ve versus $56.25 \%$-ve test $)(\mathrm{p}=0.280)$ with sensitivity $(55.56 \%)$, specificity $(71.43 \%)$ and accuracy (62.5\%) (Table 6). There was significant difference between positive \& negative UMT and each of the following: higher parasitemia (malarial index) (p 0.016), lower GCS scores (p 
0.022), lower mean platelet count (p 0.015) and severity of malaria (p 0.002) (Table 7).
As regards outcome, 51 patients $(98.08 \%)$ recovered completely without sequalae while only 1 patient died from renal failure.

Table (1): Personal data of the studied malarial patients

\begin{tabular}{|c|c|c|c|c|c|c|c|}
\hline Age Group * & Number $(\%)$ & \multicolumn{3}{|c|}{ Range } & Mean & \pm & SD \\
\hline$\leq 17$ Years & $5(9.62)$ & - & - & - & - & - & - \\
\hline$>17$ Years & $47(90.38)$ & - & - & - & - & - & - \\
\hline Total & $52(100)$ & 5 & - & 62 & 31.42 & \pm & 12.61 \\
\hline Variables & Number & \multicolumn{6}{|c|}{$\%$} \\
\hline \multicolumn{8}{|l|}{ Sex: } \\
\hline Male & 41 & \multicolumn{6}{|c|}{78.85} \\
\hline Female & 11 & \multicolumn{6}{|c|}{21.15} \\
\hline \multicolumn{8}{|l|}{ Nationality } \\
\hline Egyptian travelers** & 15 & \multicolumn{6}{|c|}{$28.85 \%$} \\
\hline Visitors & 37 & \multicolumn{6}{|c|}{$71.15 \%$} \\
\hline North Sudan & 18 & \multicolumn{6}{|c|}{$34.62 \%$} \\
\hline Nigeria & 10 & \multicolumn{6}{|c|}{$19.23 \%$} \\
\hline Chad & 4 & \multicolumn{6}{|c|}{$7.69 \%$} \\
\hline South Sudan & 2 & \multicolumn{6}{|c|}{$3.85 \%$} \\
\hline Gambia & 1 & \multicolumn{6}{|c|}{$1.92 \%$} \\
\hline Genia & 1 & \multicolumn{6}{|c|}{$1.92 \%$} \\
\hline Malawi & 1 & \multicolumn{6}{|c|}{$1.92 \%$} \\
\hline
\end{tabular}

$*$ Median for age $=29.5$ years

**Egyptian travelers were coming from North Sudan (4 patients), Nigeria (3 patients), South Sudan (2 patients), Genia (2 patients) and 1 patient coming from each of Congo, Ghana, Malaysia and Uganda.

Table (2): Clinical characteristics of the studied malarial patients

\begin{tabular}{|l|c|c|}
\hline \multicolumn{1}{|c|}{ Clinical presentation } & Number & \% \\
\hline Conscious level (GCS)* & & 78.72 \\
\hline 15 (fully conscious) & 41 & 9.60 \\
\hline $13-14$ (minor affection) & 5 & 1.92 \\
\hline $9-12$ (moderate affection) & 5 & \\
\hline$<9$ (severe affection) & & 71.04 \\
\hline Patient looks & 37 & 25 \\
\hline Normal & 13 & 11.54 \\
\hline Pale & 6 & 3.84 \\
\hline Jaundiced & 2 & 100 \\
\hline Cyanotic & 52 & 50 \\
\hline Fever & 26 & 46.15 \\
\hline Vomiting & 24 & 42.24 \\
\hline Abdominal pain & 22 & 17.3 \\
\hline Acidotic like breathing & 9 & 5.77 \\
\hline Hepatomegaly and/or splenomegaly & 3 & 5.77 \\
\hline Oliguria or anuria & 3 & 3.84 \\
\hline Prostration & 2 & 3.84 \\
\hline Multiple convulsions** & 2 & \\
\hline Pulmonary edema & 3 & \\
\hline GCS was used & 3 & \\
\hline
\end{tabular}

* GCS was used for assessment of adults $>17$ years old and Modified GCS was used for assessment of children 5 - $\leq 17$ years. **These two of patients had cerebral malaria and there GCS $<11$. 
Table (3): Laboratory characteristics and ABG of the studied malarial patients

\begin{tabular}{|c|c|c|c|c|c|c|}
\hline \multirow{2}{*}{$\begin{array}{ll} & \text { Variables } \\
\text { CBC } & \\
\end{array}$} & \multicolumn{3}{|c|}{ Range } & \multirow{2}{*}{ Mean } & \multirow[t]{2}{*}{ \pm} & \multirow[t]{2}{*}{ SD } \\
\hline & & & & & \\
\hline $\mathrm{Hb}(\mathrm{gm} / \mathrm{dl})$ & 5.1 & - & 16.8 & 10.81 & \pm & 2.65 \\
\hline TLC $\left(\times 10^{3}\right) / \mu \mathrm{mm}$ & 2 & - & 18.5 & 6.69 & \pm & 3.72 \\
\hline PLT $\left(\times 10^{3}\right) / \mu \mathrm{mm}$ & 12 & - & 202 & 74.88 & \pm & 38.72 \\
\hline \multicolumn{7}{|l|}{ Kidney functions } \\
\hline Urea $(\mathrm{mg} / \mathrm{dl})$ & 10 & - & 223 & 46.46 & \pm & 54.67 \\
\hline Creatinine $(\mathrm{mg} / \mathrm{dl})$ & 0.2 & - & 6 & 1.62 & \pm & 1.20 \\
\hline \multicolumn{7}{|l|}{ Liver profile } \\
\hline \multicolumn{7}{|l|}{ S. Bilirubin } \\
\hline$>$ Total $(\mathrm{mg} / \mathrm{dl})$ & 0.1 & & 28 & 2.36 & \pm & 5.18 \\
\hline$>$ Direct $(\mathrm{mg} / \mathrm{dl})$ & 0.2 & - & 3 & 1.31 & \pm & 1.01 \\
\hline INR & 1 & - & 1.2 & 1.10 & \pm & 0.01 \\
\hline $\operatorname{ABG}\left(\mathrm{Hcos}_{3}\right.$ level $)(\mathrm{mEq} / \mathrm{l}) *$ & 12 & - & 28 & 23.69 & \pm & 3.65 \\
\hline
\end{tabular}

*Normal bicarbonate level 22 - $28 \mathrm{mEq} / \mathrm{l}$.

Table (4): Results of parasitological study of the studied malarial patients

\begin{tabular}{|c|c|c|c|c|c|c|}
\hline \multicolumn{1}{|c|}{ Variables } & \multicolumn{3}{|c|}{ Range } & \multicolumn{3}{|c|}{ Mean } \\
\hline $\begin{array}{l}\text { Blood film microscopy* } \\
\text { (parasitological index \%) }\end{array}$ & 0.1 & - & 6 & 0.98 & \pm & 1.17 \\
\hline Variables & \multicolumn{3}{|c|}{ N } & \multicolumn{3}{|c|}{$\%$} \\
\hline Rapid Blood Test (RBT) & \multicolumn{3}{|c|}{0} \\
\hline Negative & \multicolumn{3}{|c|}{0} & \multicolumn{3}{|c|}{0} \\
\hline Positive & \multicolumn{3}{|c|}{52} & \multicolumn{3}{|c|}{50} \\
\hline Urine Malaria Test (UMT) & \multicolumn{3}{|c|}{50} \\
\hline Negative & \multicolumn{3}{|c|}{26} & \multicolumn{2}{|c|}{50} \\
\hline Positive & \multicolumn{3}{|c|}{26} & \\
\hline
\end{tabular}

* Blood film microscopy was positive for Pf malaria in all studied patients.

Table (5): Site of hospital admission of the studied malarial patients in relation to disease severity.

\begin{tabular}{|l|c|c|c|}
\hline \multicolumn{1}{|c|}{ Severity } & $\mathbf{N}$ & $\mathbf{\%}$ & Hospital admission \\
\hline Uncomplicated malaria & 36 & 69.12 & Ward \\
\hline Severe malaria* & 16 & 30.72 & ICU \\
\hline High parasitological index $>4 \%$ & 3 & 5.76 & ICU \\
\hline GCS $<11$ & 6 & 11.52 & ICU \\
\hline Prostration & 3 & 5.76 & ICU \\
\hline Multiple convulsions & 2 & 3.84 & ICU \\
\hline Metabolic acidosis $\left(\mathrm{HCO}_{3}-<15\right)(\mathrm{mEql} / \mathrm{l})$ & 3 & 5.76 & ICU \\
\hline S. Bilirubin $>3(\mathrm{mg} / \mathrm{dl})$ & 6 & 11.52 & ICU \\
\hline Renal failure & 3 & 5.76 & ICU \\
\hline Pulmonary edema & 2 & 3.84 & ICU \\
\hline Pregnancy & 1 & 1.92 & ICU \\
\hline Children** & 5 & 9.60 & Ward** \\
\hline
\end{tabular}

*One or more than one manifestation(s) of WHO criteria of severe malaria were present in studied malarial patient(s).

**These 5 children aged $\leq 17$ years were indicated for ICU admission according to WHO recommendations but they were admitted to ward because of lack of hospital ICU beds at time of their hospital admission. They were meticulously followed up by ICU specialists and none of them developed clinical nor laboratory data of severe malaria until recovery and discharge from hospital. 
Table (6): Results of UMT in relation to parasitological index in thick blood films

\begin{tabular}{|c|c|c|c|c|c|c|c|c|}
\hline \multirow{3}{*}{ UMT } & \multicolumn{6}{|c|}{ Index in thick blood film } & \multirow{2}{*}{\multicolumn{2}{|c|}{ Chi-Square }} \\
\hline & \multicolumn{2}{|c|}{$0.1 \% *$} & \multicolumn{2}{|c|}{$>0.1-\leq 0.5 \%$} & \multicolumn{2}{|c|}{ Total } & & \\
\hline & $\mathbf{N}$ & $\%$ & $\mathbf{N}$ & $\%$ & $\mathbf{N}$ & $\%$ & $\mathbf{X 2}$ & P-value \\
\hline Negative & 5 & 71.43 & 4 & 44.44 & 9 & 56.25 & \multirow[t]{3}{*}{1.165} & \multirow[t]{3}{*}{0.280} \\
\hline Positive & 2 & 28.57 & 5 & 55.56 & 7 & 43.75 & & \\
\hline Total & 7 & 100 & 9 & 100 & $\overline{16}$ & 100 & & \\
\hline \multicolumn{2}{|c|}{ Sensitivity } & \multicolumn{2}{|c|}{ Specificity } & \multicolumn{2}{|c|}{ PPV } & & \multicolumn{2}{|c|}{ Accuracy } \\
\hline \multicolumn{2}{|c|}{55.56} & \multicolumn{2}{|c|}{71.43} & \multicolumn{2}{|c|}{71.43} & & \multicolumn{2}{|c|}{62.5} \\
\hline
\end{tabular}

$* 0.1 \%$ index $=4000$ parasites $/ \mu \mathrm{mm}$

Table (7): Relation between UMT results and other parameters of the studied malarial patients.

\begin{tabular}{|c|c|c|c|c|c|c|c|c|}
\hline Variables & \multicolumn{6}{|c|}{ UMT } & Test & P-value \\
\hline GCS & \multicolumn{3}{|c|}{ Negative (26 patients) } & \multicolumn{3}{|c|}{ Positive (26 patients) } & \multirow{3}{*}{$\begin{array}{c}t= \\
2.35\end{array}$} & \multirow{3}{*}{$\begin{array}{c}0.022^{*} \\
(\mathrm{~S})\end{array}$} \\
\hline Range & 12 & - & 15 & 8 & - & 15 & & \\
\hline Mean \pm SD & 14.84 & \pm & 0.61 & 13.88 & \pm & 1.98 & & \\
\hline \multicolumn{7}{|l|}{ Platelet count } & \multirow{3}{*}{$\begin{array}{c}\mathrm{t}= \\
2.52\end{array}$} & \multirow{3}{*}{$\begin{array}{c}0.015^{*} \\
(\mathrm{~S})\end{array}$} \\
\hline Range & 30 & - & 202 & 12 & - & 130 & & \\
\hline Mean \pm SD & 87.76 & \pm & 39.61 & 62.00 & \pm & 33.834 & & \\
\hline \multicolumn{7}{|l|}{ Malarial Index \% } & \multirow{3}{*}{$\begin{array}{c}t= \\
-2.49\end{array}$} & \multirow{3}{*}{$\begin{array}{c}0.016^{*} \\
(\mathrm{~S})\end{array}$} \\
\hline Range & 0.1 & - & 1 & 0.1 & - & 6 & & \\
\hline Mean \pm SD & 0.59 & \pm & 0.32 & 1.37 & \pm & 1.55 & & \\
\hline \multirow[t]{2}{*}{ Severity } & \multicolumn{3}{|c|}{ Negative (26 patients) } & \multicolumn{3}{|c|}{ Positive (26 patients) } & \multirow{4}{*}{$\begin{array}{c}X 2= \\
9.33\end{array}$} & \multirow{4}{*}{$\begin{array}{c}0.002^{*} \\
(\mathrm{~S})\end{array}$} \\
\hline & $\mathrm{N}$ & & $\%$ & $\mathrm{n}$ & & $\%$ & & \\
\hline Mild & \multicolumn{2}{|c|}{25} & 96.15 & \multicolumn{2}{|c|}{16} & 61.54 & & \\
\hline Severe & \multicolumn{2}{|l|}{1} & 3.85 & \multicolumn{2}{|l|}{10} & 38.46 & & \\
\hline
\end{tabular}

*S: significant.

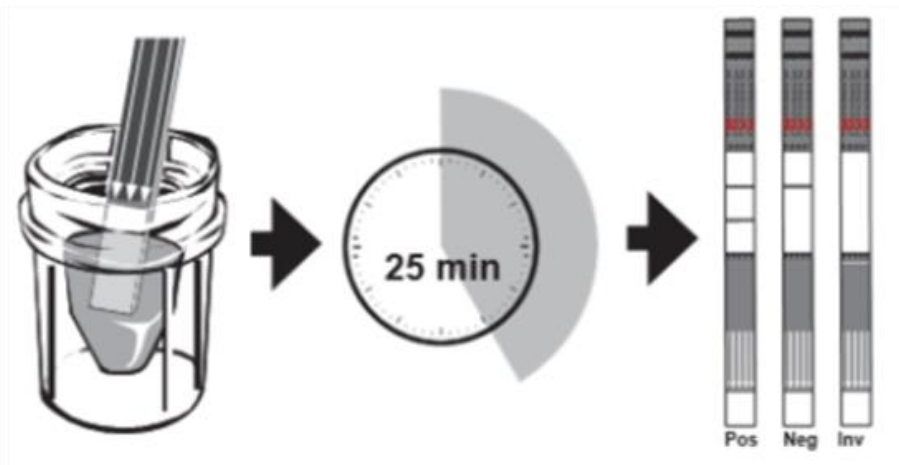

Figure (1): Diagram of rapid diagnostic Urine Malaria Test. 


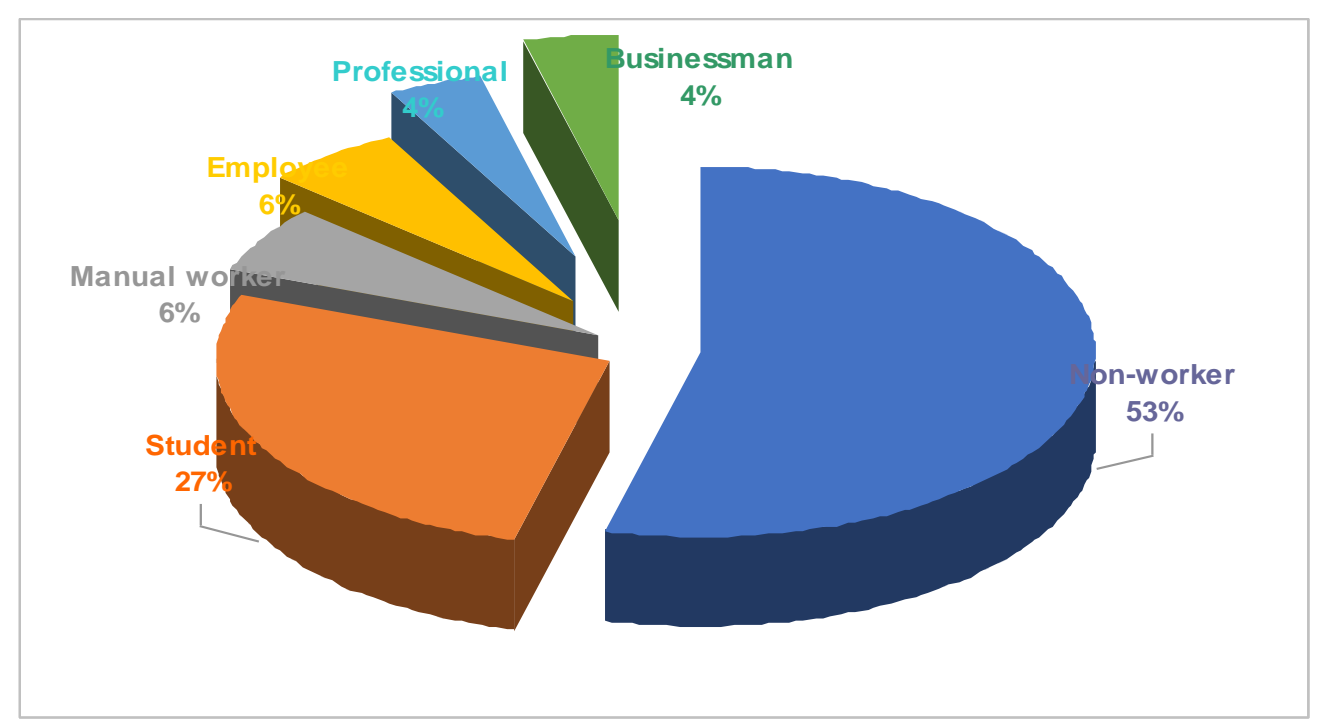

Figure (2): Shows the occupational of the studied malarial patients

\section{DISCUSSION}

In the present study, the mean age value was $31.42 \pm 12$ years with median age (30.5 years). These results disagreed with Kulkarni \& Agrawal, (higher mean age value was reported) [9] and Nwakanma et al. (reported lower median age value) [10]. Satpathy et al. [11] and Abdullahi et al. [12] reported that $90.3 \%$ and $43.77 \%$ of their cases aged $<18$ years and $\leq 5$ years respectively.

The present study reported higher incidence of malaria in males $(78.85 \%)$ than females $(21.15 \%)$ with ratio 3.72: 1 . The higher male sex predilection was in agreement with Satpathy et al. [11], Nandwani et al. [13], Oguonu et al. [5] and Kulkarni \& Agrawal [9] however they reported lower male to female ratios (1.6: 1, 1.22: 1, 1.7: 1, and 1.87: 1 respectively). On the other hand, Nwakanma et al. [10] and Onwujekwe et al. (14) reported higher incidence of malaria in females.

The present study revealed that about one half of cases were non-workers $(53.85 \%)$ and about one fourth $(26.92 \%)$ were students. These results disagreed with Onwujekwe et al. [14] and Dysoley et al. [15] who suggested that workers engaged in inferior occupation categories have higher risk of malaria due to their outdoor sleeping, frequent movement and inadequate treatment. Also, Sharma et al. suggested that the occupation (not the level of education) of the household head has significant impact on malaria occurrence [16].

As regards the clinical characteristics of the studied patients, the present study revealed that fever was a constant finding in all cases followed by vomiting $(50 \%)$, abdominal pain $(46.15 \%)$, acidotic like breathing (42.24\%), pallor (25\%) and various degrees of disturbed conscious level $(21.15 \%)$. Other apparent less frequent features were Hepatomegaly and/or splenomegaly (17.3\%), jaundice $(11.54 \%)$, prostration and oliguria or anuria (5.77\% for each) and pulmonary edema, convulsions and cyanosis (3.84\% for each). These results agreed with Kulkarni \& Agrawal [9] and Nandwani et al. [13] regarding the presence of fever in all cases while there were disagreement with them regarding the occurrence of other clinical features as they included large number of patients (300 malarial patients) in their study. On the other hand, Mharakurwa et al; reported asymptomatic infection in all studied malarial patients except for two febrile cases with highest parasite density. The authors used PCR methods for malaria detection and they stated that this method detect much lower parasitemia that other methods do so even before the beginning of symptoms [17].

In the present study the mean value of total and direct serum bilirubin were 2.36 and $1.31 \mathrm{mg} / \mathrm{dl}$ respectively and 6 patients $(11.54 \%)$ presented by serum bilirubin $>2 \mathrm{mg} / \mathrm{dl}$ while serum bilirubin was $>3 \mathrm{mg} / \mathrm{dl}$ in 4 of them. These results disagreed with the results of Naqvi et al. [18] and Kulkarni and Agrawal [9] who reported higher mean serum bilirubin values with jaundice present in $50 \%$ and $8 \%$ of their patients respectively.

In the present study the mean values of blood urea and serum creatinine were $(46.46 \pm 54.67$ and $1.62 \pm 1.20)$ respectively. Three out of 52 patients $(5.77 \%)$ developed acute renal failure. These results disagreed with Naqvi et al. [18] 
and Kulkarni \& Agrawal [9] who reported higher mean values of blood urea and serum creatinine with evidences of acute renal failure in $68 \%$ in the former study which to determine the outcome of severe acute renal failure in their malarial patients and $10 \%$ in the later study which included large number of patients.

The present study revealed that the mean platelet value was $74.88 \pm 38.72 \times 103 / \mu \mathrm{mm}$ and thrombocytopenia $<90 \times 103 / \mu \mathrm{mm}$ was present in $73.07 \%$ of patients. The mean hemoglobin level was $10.81 \pm 2.65 \mathrm{gm} / \mathrm{dl}$ with severe anemia $(\mathrm{Hb}<7$ $\mathrm{gm} / \mathrm{dl}$ ) was present in 21.15 of patients. Naqvi et al. reported lower mean $\mathrm{Hb}$ level and higher mean Platelet count when compared with our results (18). Kulkarni \& Agrawal [9] and Nayak et al. [19] reported hypoxia-metabolic acidosis in $15 \%$ (higher than our results) and 7\% (close to our results) respectively.

The outcome of studied malarial patients showed complete recovery in 51 patients $(98.07 \%)$ and death in 1 patient (1.92\%). These results disagreed with Satpathy et al. who concluded that the incidence of complicated falciparum malaria is still very high with multisystem involvement [11]. Zeidan et al; reported that case fatality rate was $2.6 \%$ specially in children $<9$ years and the risk of dying included delay of beginning of treatment, severe malaria association with coma, inability to sit or eat and hyperpyrexia [20]. Also, in El-Folly et al. in an Egyptian study reported that uncomplicated versus complicated malaria were present in $88 \%$ and $12 \%$ respectively and the outcome of their patients were complete cure (82\%) (lower than our results), recovery with sequelae $(10 \%)$ and recurrence $(6 \%)$ (unlike our results) and death (2\%) (close to our results) [21].

The UMT was +ve in $50 \%$ of cases with $50 \%$ false -ve results in parasitologically confirmed Pf malaria. Sixteen of the studied cases presented with parasitemia $\leq 0.5 \%$ and there was non-significant difference (p-0.280) between +ve UMT $(56.25 \%)$ and -ve UMT (43.75\%). The sensitivity, specificity, NPV and accuracy of the test in diagnosis of Pf malaria at parasitemia $\leq 0.5 \%$ were $55.56 \%$, $71.43 \%, 55.56 \%$ and $62.5 \%$ respectively. Moreover, there were significant relation between +ve UMT and higher parasitological index, lower GCS, low mean platelet count as well as severity of malaria. When these results compared with the previous studies, various results were reported. Oguonu et al. reported that $44.1 \%$ of their patients were +ve for UMT with false -ve results $12.12 \%$ in children versus $28.57 \%$ in adults (much lower than our results) and $9.74 \%$ false +ve results (this point was not assessed in the present study as we did not include febrile non malarial patients). The authors reported that the parasite rates were $41.03 \%$ and $3 \%$ among children $<18$ years and adults respectively and the overall sensitivity and specificity in comparison with malaria microscopy were $83.75 \%, 83.48 \%$ respectively [5]. Oyibo et al. reported that sensitivity and specificity of UMT among febrile patients were $85 \%$ and $84 \%$ respectively and among febrile children $\leq 5$ years of age were $93 \%$ and $83 \%$ respectively [22].

Bailey et al. suggested that it may be reasonable to make a presumptive diagnosis with the decision to initiate empiric therapy if laboratory facilities are lacking and (Pf) infection is suspected clinically [2] but WHO recommended not to start antimalarial therapy before parasite-based diagnosis to minimize the resistance to the new antimalarial drugs [1].

\section{CONCLUSION}

Although the sensitivity (55.56\%), specificity (71.43) and accuracy (62.5) of UMT in diagnosis of Pf malaria at parasitological index $\leq 0.5 \%$ were apparently low, the test might be of value in the settings of higher parasitemia, lower GCS, lower platelet count and severe disease.

Therefore, we recommend further studies in large number of patients from different geographic areas, lower parasitological indices and various clinical presentations to determine the exact values of the test in early diagnosis of Pf malaria before its deployment for field use.

\section{Funding: None.}

\section{Conflicts of interest: None.}

Ethical approval:Approved ; written consents have been taken from all included patients.

\section{REFERENCES}

1. World Health Organization. Guidelines for the treatment of malaria, 3rd ed, WHO, Geneva 2015.

2. Bailey JW, Williams J, Bain BJ, Parker-Williams J, Chiodini PL; General Haematology Task Force of the British Committee for Standards in Haematology. Guideline: the laboratory diagnosis of malaria. General Haematology Task Force of the British Committee for Standards in Haematology. $\quad B r \quad J \quad$ Haematol. 2013 Dec;163(5):573-80. doi: 10.1111/bjh.12572. 
3. The full report of round 6 of the WHO malaria RDT product testing programme is available at http://www.who.int/malaria/publications/atoz/978 9241510035/en/

4. Anchinmane VT and Shedge RT. Detection of malarial parasite in urine of malaria patients: a future diagnostic approach. International Journal of Research in Medical Sciences, 2016, 4(5), 1702-1705.

5. Oguonu T, Shu E, Ezeonwu BU, Lige B, Derrick A, Umeh RE, Agbo E. The performance evaluation of a urine malaria test (UMT) kit for the diagnosis of malaria in individuals with fever in south-east Nigeria: cross-sectional analytical study. Malar J. 2014 Oct 15;13:403. doi: 10.1186/1475-2875-13-403.

6. Malaria Quick Urine Test Developed in Nigeria|Africa|DW.COM|11.05.2016. n.d. http://www.dw.com/en/malaria-quick-urine-testdeveloped-in-nigeria/a-19247753.

7. Farrar J, Hotez P, Junghanss, T, Kang G, Lalloo D and White N. Manson's Tropical Diseases; 23 ${ }^{\text {rd }}$ Edition pages, 2014, 553, 554

8. CareStart ${ }^{\mathrm{TM}}$ Malaria HRP2/pLDH(Pf/PAN) Combo by Access Bio Ethiopia. http://www.accessbio.net.

9. Kulkarni, VK , Agrawal, K. A study of clinical profile of malaria with special reference to complications and outcome. International Journal of Advances in Medicine, 2017, 4(2), 317-322.

10. Nwakanma DC, Gomez-Escobar N, Walther M, Crozier S, Dubovsky F, Malkin E, Conway DJ. Quantitative detection of Plasmodium falciparum DNA in saliva, blood, and urine. The Journal of Infectious Diseases, 2009, 199(11), 1567-1574.

11. Satpathy S, Mohanty N, Nanda P, \& Samal G. Severe falciparum malaria. The Indian Journal of Pediatrics, 2004, 71(2), 133-135.

12. Abdullahi K, Abubakar U, Adamu T, Daneji A, Aliyu R, Jiya N, Nata'ala S. Malaria in Sokoto, North Western Nigeria. African Journal of Biotechnology, 2009, 8(24).

13. Nandwani S, Pande A, Saluja M. Clinical profile of severe malaria: study from a tertiary care center in north India. Journal of Parasitic Diseases, 2014, 38(1), 11-15.
14. Onwujekwe O, Uguru N, Etiaba E, Chikezie I, Uzochukwu B, \& Adjagba A. The economic burden of malaria on households and the health system in Enugu State Southeast Nigeria. PLoS ONE, 2013, 8(11), e78362.

15. Dysoley L, Kaneko A, Eto H, Mita T, Socheat D, Börkman A, \& Kobayakawa T. Changing patterns of forest malaria among the mobile adult male population in Chumkiri District, Cambodia. Acta tropica, 2008, 106(3), 207-212.

16. Sharma RK, Singh MP, Saha K.B, Bharti PK, Jain V, Singh P, Chand S. Socio-economic \& household risk factors of malaria in tribal areas of Madhya Pradesh, central India. The Indian Journal of Medical Research, 2015, 141(5), 567.

17. Mharakurwa S, Simoloka C, Thuma PE, Shiff CJ, \& Sullivan DJ. PCR detection of Plasmodium falciparum in human urine and saliva samples. Malaria Journal, 2006, 5(1), 103.

18. Naqvi, R, Ahmad E, Akhtar F, Naqvi A, \& Rizvi A. Outcome in severe acute renal failure associated with malaria. Nephrology Dialysis Transplantation, 2003, 18(9), 1820-1823.

19. Nayak K, Kumar S, Tanwar R, Kulkarni V, Gupta A, Sharma P, Ratan P. A study on pulmonary manifestations in patients with malaria from northwestern India (Bikaner). Journal of Vector Borne Diseases, 2011, 48(4), 219.

20. Zeidan ZA, Kojal EM, Habour AB, Nowary KA, Mohammed FH, \& Awadelkareem MA. Severe malaria in sudanese children: Clinical aspects and prognosis in hospitilized patients. Journal of Family \& Community Medicine, 2005, 12(3), 127.

21. El-Folly, R., El-Sayed, A., Ezz Elarab, M. . 'An Overview Study of Malaria Infection in Almaza Military Fever Hospital; An Egyptian Pilot Study'. Afro-Egyptian Journal of Infectious and Endemic Diseases 2018; 8(1), pp. 24-33. doi: 10.21608/aeji.2018.8732

22. Oyibo WA, Ezeigwe N, Ntadom G, Oladosu OO, Rainwater-Loveth K, O'Meara W, Brieger W. Multicenter pivotal clinical trial of urine malaria test for rapid diagnosis of Plasmodium falciparum malaria. Journal of Clinical Microbiology 2017, 55(1), 253-263. 